\title{
DECLAMACIÓN Y ORATORIA BAJO AUGUSTO: A PROPÓSITO DE CASIO SEVERO, ALBUCIO SILO Y PORCIO LATRÓN
}

\author{
PABLO SCHWARTZ* \\ Universidad de la República \\ (Montevideo, Uruguai)
}

\begin{abstract}
RESUMO: Sêneca o Retor apresenta o retrato mais completo de que se dispõe sobre a declamação em Roma. Esta prática, considerada como un exercício escolar que prepara os jovens para a eloquencia forense ou deliberativa, transforma-se num gênero independente. Este fato, de vastas consequências para a história da literatura ocidental, é analisado a partir do desempenho no foro e nas salas de declamação de três oradores e declamadores: Albúcio Silo, Pórcio Latrão e Cássio Severo. Estes exemplos mostram um relacionamento tenso entre declamação e oratória, mas também deixam ver uma eloquência adaptada à expressão do tempo presente.
\end{abstract}

PALAVRAS-CHAVE: Sêneca o Retor; declamação; eloqüência; oratória.

El término declamatio designa desde los tiempos finales de la república principalmente los ejercicios oratorios realizados a imitación de las causas judiciales (controversiae) o de los discursos deliberativos (suasoriae). Las controversias enfrentaban dos posiciones en un proceso ficticio. Los expositores defendían una u otra de las partes en litigio. Las argumentaciones podían invocar leyes -a veces imaginarias- en favor de la tesis defendida. Las suasorias eran discursos deliberativos dirigidos a personajes históricos o mitológicos para convencerlos de actuar de determinada manera. Así Juvenal, en su primera sátira (vv. 15-17), para significar que tiene la formación requerida para escribir, es decir, que ha asistido al aula del retórico, confiesa haber declamado para convencer a Sila ${ }^{1}$ de abdicar de la dictadura:

Después de todo también nosotros sustrajimos la mano a la palmeta, también nosotros aconsejamos a Sila que se retirara a la la vida privada para dormir tranquilo. ${ }^{2}$ 
Sabemos que en su juventud Cicerón declamaba en griego, y continuó haciéndolo en latín hasta sus últimos años. El daba el nombre de causae ${ }^{3}$ a lo que en tiempos de Séneca el Viejo se llamaba controversiae, y consideraba a estas prácticas un entrenamiento útil para la oratoria ${ }^{4}$ y acaso una distracción de las preocupaciones. Solía declamar con Hircio y Pansa, a quienes llamaba "sus discípulos" y grandis praetextatos, algo así como "adultos adolescentes" . Hircio y Pansa, pues, realizaban al declamar una actividad inusual, en la época, para un adulto ${ }^{6}$.

La voz declamatio, según refiere Séneca el Viejo (Contr. I praef. 12), no aparece antes de Cicerón y de Calvo. Este último la habría considerado como un tipo de ejercicio doméstico (domesticae exercitationis), estableciendo de ese modo una distinción entre la declamación, entendida como un discurso de entrenamiento, y el discurso forense, valorado como una verdadera acción (verae actionis). ${ }^{7}$ En el Brutus (90, 309-310) Cicerón vincula la declamación a la dialéctica y recuerda sus ejercicios con el estoico Diodoto. Considera a la oratoria como una dialéctica extendida, añade que practicaba diariamente la declamación, y destaca que este término, conforme a lo referido por Séneca, es de uso reciente. ${ }^{8}$

La penetración de la enseñanza oratoria, que impuso la práctica de tales ejercicios en Roma había tenido que vencer fuertes resistencias. Suetonio (De gram. et rhet. 25, 1) cita dos textos que ejemplifican el rechazo desde el estado a la irresistible ascensión de la enseñanza retórica: un escueto senatus consultus del año 161 a.C. y un edicto de los censores promulgado en el 92 a.C. El primero es relativo a la expulsión de los filósofos y retores de Roma. El edicto es bastante ilustrativo del temor que infundía a los tradicionalistas la propagación de la enseñanza oratoria impartida ahora por roma$\operatorname{nos}^{10}$ :

Los censores Cn. Domicio Ahenobarbo y L. Licinio Craso dispusieron lo siguiente: "Se nos ha informado acerca de personas que crearon una nueva clase de enseñanza, a cuyas escuelas concurre la juventud; que ellos se han dado a si mismos el nombre de retores latinos; y que allí hombres jóvenes malgastan su ocio días enteros. Nuestros mayores instituyeron qué cosas querían que sus hijos aprendieran y a qué escuelas debían concurrir. Estas novedades, que van más allá de las costumbres y prácticas de nuestros mayores, no las aprobamos ni nos parecen honestas. Por lo cual creemos nuestra obligación manifestar a los que tienen tales escuelas y a quienes concurren regularmente a ellas nuestro parecer: no cuentan con nuestra aprobación. ${ }^{11}$ 
El sesgo tradicionalista y moralizante del edicto, que opone haec nova a las consuetudinem ac morem maiorum reaparece en referencias posteriores al mismo. En el De oratore (III, 93) Craso, personaje del diálogo, y uno de los responsables de dicho edicto, se defiende de la acusación de haber impedido que los jóvenes desarrollasen su ingenio. ${ }^{12}$ Alega que su objetivo fue que este ingenio no se debilitase, al tiempo que se robustecía la desvergüenza. ${ }^{13}$ En el Dialogus de oratoribus $(35,1)$ de Tácito, citando el texto de Cicerón, Mesala alude al edicto como clausura de la "escuela de la desvergüenza". A partir de estas referencias podemos inferir que se criticaba además de la predilección de los declamadores por temas escabrosos, la creciente autonomía de las declamaciones como ejercicios de imaginación. Tanto en las controversias, como en las suasorias, es indudable la preponderancia de la especulación sin finalidad ulterior necesaria, y de una imaginación poético-literaria en la construcción de caracteres y situaciones.

También puede conjeturarse como motivo de estas críticas y otras - que se convertirán en tópicas- sobre la falta de realidad de estos ejercicios, el hecho de que más allá del carácter imaginativo y fantasioso de los mismos, se manifiesta una crítica de instituciones y costumbres, un cierto malestar de la cultura, del que Ovidio sería un exponente característico. ${ }^{14}$ Entre las prácticas que Suetonio (De gram. et rhet. 25,8 ) menciona como antecedentes históricos de las controversias, hay una que consiste en hacer aparecer a ciertas instituciones relativas a la vida cotidiana, ya como útiles y necesarias, ya como perniciosas y superfluas. ${ }^{15}$ Además de la aspiración a desarrollar la capacidad dialéctica del alumno, que debía estar preparado para defender puntos de vista opuestos, parece evidente que esta clase de ejercicios podía desembocar fácilmente en la crítica social y política. Así los conflictos entre el derecho y la norma moral, o entre las tradiciones fosilizadas y la libertad individual constituyen un tipo de situación recurrente en las controversias. Poco importa a estos efectos que las leyes esgrimidas no existan en el derecho positivo, o que los ambientes en que se desarrollan, se vinculen a una visión mitificada del pasado, o incluso a la historia y poesía griegas.

A partir de Augusto las salas de declamación constituyen un espacio que reúne a oradores reconocidos y aun a personalidades de la vida pública. ${ }^{16}$ Conviene distinguir aquí entre la declamación como práctica escolar de los jóvenes en el aula del retor y la declamación como espectáculo público ${ }^{17}$. En efecto en las propias escuelas de declamación se realizaban periódicamente exhibiciones públicas de las declamaciones ya preparadas por los alumnos y el retor ${ }^{18}$. No era raro que en estas ocasiones participaran activamente invitados ajenos a la escuela ${ }^{19}$. De ese modo la declamación comienza a independizarse progresivamente de la finalidad de preparar para la oratoria, y se convierte 
en un fin en si mismo. Votieno Montano (Sen. Contr. IX praef. 1), define así el objetivo del declamador en clara oposición con el del orador:

Quien prepara una declamación no escribe para vencer sino para agradar. Por eso procura todo lo que es atractivo. Como las argumentaciones son molestas y tienen poco ornamento, las deja de lado, y se siente satisfecho si logra seducir a sus oyentes mediante sentencias y desarrollos. Desea conseguir la aprobación para si mismo, no para la causa. ${ }^{20}$

A juicio de Norden (Norden, 1986, v. 1, p. 260), es en las salas de declamación donde se manifiesta más intensamente el ocio que trajó Augusto a su tiempo. La reducción del campo de acción de la oratoria política, habría trasladado al ámbito de la declamación el antiguo deseo de brillar en la elocuencia pública. El estilo y el público se sofistican, las exigencias de verosimilitud y sumisión al marco jurídico real desaparecen, y bajo esta influencia los distintos géneros se apartan progresivamente de las convenciones del arte clásico. ${ }^{21}$

Sería un error, sin embargo, dar una dimensión exagerada al divorcio entre declamación y oratoria. Suetonio (De gram. et rhet. 25, 7) afirma que la mayor parte de los oradores publicó declamaciones, al tiempo que muchos maestros de retórica, de humilde origen, llegaron al orden senatorial y a los mayores honores. ${ }^{22}$ De modo similar, en el Dialogus de oratoribus, Apro, personaje que aparece vinculado a las aulas de declamación, ${ }^{23}$ al destacar el vigor de la oratoria contemporánea y su utilidad como motor de ascenso social, parece negar la mentada inadecuación entre educación retórica - basada en la declamación - y práctica forense y aun deliberativa. ${ }^{24}$

A continuación trataremos de indagar el modo en que oratoria y declamación se presentaban como opuestas irreconciliables, partiendo del mal desempeño de algunos declamadores en el ámbito forense. Nos serviremos para ello principalmente de algunos pasajes de la obra de Séneca el Viejo. Digamos antes unas pocas palabras sobre la misma.

\section{Séneca el Viejo}

Lucio Anneo Séneca nació en Córdoba, España, en los años previos al 50 a.C, y murió pocos años antes del exilio de su hijo, probablemente en el año 39 de nuestra era. Estudió retórica con el retor Marulo (Contr. I pr. 22) en Roma, donde pasó la mayor parte de su vida. Escribió una obra, hoy perdida, sobre historia romana 
reciente, y el texto que nos ocupa, sobre oradores y declamadores de los primeros tiempos del imperio, que no ha llegado íntegro hasta nosotros. Se lo conoce como Controversias y Suasorias, o simplemente Declamaciones, aunque el título que se ha conservado podría traducirse como Sentencias, divisiones y colores de los oradores y retores. ${ }^{25}$ Se trata de un registro - el más completo de que disponemos - sobre las declamaciones, en sus dos formas, suasorias y controversias. Séneca transcribe para sus hijos, destinatarios de la obra, discursos oídos en su juventud en las salas de declamación y una variedad de jugosas anécdotas y reflexiones relativas a sus protagonistas, los declamadores (rhetores) y también a oradores (oratores), que añadían a su actividad en el foro o en el senado participaciones ocasionales en las salas de declamación.

Parte del encanto que la lectura de Séneca el Viejo puede ofrecer a un lector contemporáneo podría justificarse por la asistematicidad que impregna su relato y por su tono fuertemente subjetivo. La minuciosidad un poco fatigante con que transcribe a veces ligeras variantes argumentales de las controversias, se matiza con el humor y la ironía presentes en sus anécdotas y comentarios sobre los declamadores. Séneca no se propone ser un observador imparcial de lo que narra. Interviene, evalúa, alaba y censura. Por eso sus juicios son un elemento precioso a la hora de establecer los criterios con que se valoraban en su tiempo las manifestaciones de este género peculiar. Hay además en su texto cierto desorden que es programático. El autor advierte que se someterá a los caprichos de su memoria de anciano para narrar los recuerdos de los declamadores de su tiempo:

Es inevitable pues que me mueva al azar por mis antiguos estudios y tome lo que se presente a mi memoria. Puede ocurrir que coloque en lugares diversos sentencias pronunciadas en una sola controversia: no siempre que busco algo consigo encontrarlo; pero a menudo, un recuerdo que no compareció a mi llamado, se presenta cuando estoy tratando de otra cosa (...) A veces cuando estoy ocupado en un asunto serio, una sentencia largamente procuarada viene a importunarme. Es preciso, pues, que me adapte a los caprichos de mi memoria que ya hace tiempo solo me obedece de un modo precario (Contr. I praef. 4-5).

Entre los numerosos oradores y declamadores de que nos habla Séneca, vamos a referirnos a tres, a partir de cuyos retratos surge con bastante claridad la oposición entre oratoria y declamación: Albucio Silo, Porcio Latrón y Casio Severo. Albucio aparece retratado en el prefacio del libro séptimo de controversias; Latrón, en el del primero y Casio Severo, en el del tercero. Los dos primeros, muy especialmente Latrón, 
participan reiteradamente en las controversias. Los prefacios de cada uno de los libros de controversias que se han conservado, no siempre de forma íntegra, presentan en todos los casos como figura destacada a un orador, ${ }^{26}$ ya a través de referencias de Séneca, ya a través de la transcripción de sus propias opiniones.

\section{Albucio Silo}

En primer lugar nos referiremos a Albucio Silo. Séneca lo presenta (Contr. VII praef. 2) como un hombre brillante, pero inseguro:

No se si existió tal brillo de estilo en algún otro. Su dicción era superior a su facilidad: Pronunciaba con velocidad y fluidez, pero luego de haberse preparado. Los que lo conocieron mejor afirman que no le faltaba capacidad de improvisar, pero él creía que le faltaba.

Séneca destaca su falta de medida en el tratamiento de las controversias, ya que no era capaz de distinguir lo fundamental de lo accesorio. El desarrollo de un tema lateral podía convertirse en una nueva controversia, de modo que nunca terminaba lo que comenzaba:

Pretendía decir en cada controversia no todo lo que debía decirse, sino todo lo que podía decirse. Argumentaba con más pesadez que sutileza. Acumulaba un argumento sobre otro y como generalmente nada le parecía suficientemente sólido, afirmaba todas las pruebas con otras pruebas (ib. praef. 1).

Podía hablar durante horas sin detenerse y era agradable oírlo aunque uno se arrepintiese a veces de haberlo hecho ${ }^{27}$ Su gusto era mudable y excesivamente sujeto a las influencias, por lo que su estilo no mejoró con la edad; por el contrario:

No tenía ninguna confianza en su talento, de ahí sus frecuentes cambios. Así pasaba de un estilo oratorio a otro: ya quería ser seco y ajustarse simplemente a las ideas, ya hórrido y vigoroso antes que pulido, ya breve y armonioso; algunas veces se elevaba mucho, y otras, descendia demasiado. Así malgastó su talento y cuando llegó a la vejez hablaba mucho peor de lo que lo hacía en su juventud (Contr. VII, praef. 5). ${ }^{28}$ 
Su carrera de orador quedó marcada por un episodio vergonzoso: Según explica Séneca, se alejó del foro como resultado del uso inapropiado de una figura en un juicio ante los centumviros. En un momento de su alegato exhortó a su adversario a prestar un juramento y acabar de ese modo la causa: ${ }^{29}$

" $i$ Quieres poner fin a este juicio con un juramento? Jura entonces pero yo estableceré la fórmula: jura por las cenizas de tu padre, que aún no has sepultado, jura por la memoria de tu padre," y así desarrolló aquel recurso. Cuando hubo acabado, se levantó Lucio Arruntio, que representaba a la otra parte y dijo: "Aceptamos la propuesta. Él ${ }^{30}$ va a jurar". Albucio se puso a gritar: "No hice ninguna propuesta. Dije una figura." Arruntio insistía. Los centumviros se apresuraban para que acabara el juicio. Albucio volvió a gritar: "Con este criterio se suprimen las figuras de retórica" Arruntio contestó: "Que se supriman, podremos vivir sin ellas." El fin de la causa fue el siguiente. Los centumviros dijeron que darían un dictamen favorable al adversario de Albucio si éste juraba, y él juró (Contr. VII praef. 7).

El costado cómico y patético del personaje radica en su aislamiento de la realidad, en su desconocimiento total del auditorio al que se enfrentaba. Esta realidad, la de los juicios civiles y penales, no era alentadora. En todo caso, a través de esta anécdota Séneca no nos transmite una imagen demasiado simpática del sistema de justicia. No lo suficiente como para fundar en ella algún tipo de ideal, como el que defendía, por ejemplo, Quintiliano. Los centumviros están preocupados para terminar con el caso pronto. En el Dialogus ... (19, 4-5) ésta aparece como la situación corriente. Más aún, se dice que los jueces suelen actuar más con arreglo a la violencia de su poder discrecional que con afán de justicia. ${ }^{31}$ De este modo, el reverso del ridículo a que es sometido Albucio es la inmoralidad del sistema judicial. Su empeño en utilizar figuras a cualquier precio, sin el menor sentido de la oportunidad, no solo es una manifestación de una oratoria decadente y carente de decorum, también es la denuncia de una oratoria que se ha vuelto mercantil. ${ }^{32}$

También Suetonio se refiere a Albucio. Lo hace en el capítulo final del De grammatibus et rhetoribus. En 30, 5, asistimos a una versión más concisa del mismo episodio, cuya introducción hace más explícita la falta de decorum, de adecuación a la situación, por parte de Albucio, ya que éste acusaba al reo de impiedad en relación a sus padres, ${ }^{33} \mathrm{y}$ parece por lo menos poco prudente ofrecer un juramento por las cenizas del padre a alguien a quien se acusa de falta de piedad filial. Suetonio reseña otros 
episodios de su vida que testimonian esta misma inadecuación. Al comienzo de su relato sobre Albucio, nos cuenta cómo huyó de su patria, luego que fue retirado por los pies del tribunal desde el que impartía justicia, por aquellos contra quienes se pronunciaba $(30,1)$. Luego de un agitado y matizado periplo vital que incluye Roma y Milán, vuelve, anciano y enfermo a su patria. Convoca al pueblo, y después de extenderse, a modo de arenga, sobre las causas por las que había decidido morir, dejó de alimentarse $(30,7)$.

Esta falta de plasticidad en su actuación pública aparece como contradictorio correlato de su volubilidad estética. En última instancia, su discurso ante el pueblo, anunciando su muerte, aunque destaca un elemento teatral (declamar sobre la propia muerte) que es casi una parodia de sí mismo, también introduce cierta idea de compensación, muy cara al pensamiento romano. Albucio, que ha vacilado toda su vida, ha cambiado sus modelos, sus gustos, ha dejado que su talento lo traicionara, ha sido en fin, juguete del destino, revela en la hora de su muerte una firmeza insólita.

\section{Porcio Latrón}

Es sin duda la figura más destacada de las recordadas por Séneca en sus controversias y suasorias. Ocupa el primer rango entre los declamadores mencionados. Amigo del autor, como él, había partido desde España hacia Roma. Allí fueron condiscípulos en las aulas del retor Marulo. El afecto que por él demuestra Séneca no lo salva, sin embargo, de críticas. Nuestro autor parece asistir con un asombro divertido al desorden vital del amigo:

Este hombre apasionado carecía de moderación en dos sentidos: no sabía interrumpir su trabajo y no sabía retomarlo (Contr. I praef. 13). ${ }^{34}$

Nos informa Séneca (Contr. I, praef. 14-15) que cuando estaba escribiendo podía olvidarse de dormir y no abandonaba la actividad, sino cuando desfallecía. Pero cuando decidía descansar, se entregaba a la caza y a la vida agreste sin moderación. Estos prolongados intervalos de ocio refrescaban su elocuencia, que lograba entonces expresar cuanto quisiera. Séneca concluye este primer esbozo del amigo, que se ampliará en el resto de la obra, con un juicio severo y compasivo de este hombre que poseía un talento incapaz de gobernarse:

Por eso debía habérsele cercenado esta pasión, (i.e: la de escribir) porque no podía ser regulada. Así, cuando se abatía por el esfuerzo frecuente 
e ininterrumpido, su ingenio experimentaba una fatiga que no es menor que la corporal, pero está más oculta (Contr. I praef. 15).

Uno de los trazos característicos del arte declamatorio, y de la literatura latina imperial, es el uso de la sententia, la frase de ingenio, fuertemente condensada y tendiente a realzar las contradicciones. Los hijos de Séneca, destinatarios de la obra, quieren oír sententiae, y su padre les señala que Latrón se mostraba magistral en el uso de éstas. La frase de ingenio con que interrumpe a su maestro es característica del humor corrosivo propio del estilo declamatorio:

También Latrón se caracterizaba por amar las sentencias. Cuando eramos condiscípulos en la escuela del retor Marulo, hombre bastante árido, que se expresaba muy brevemente, con brillo, y en un estilo no vulgar, en un momento en que éste atribuía la pequeñez de su discurso al tema de la controversia y decía: "Es preciso que pise con cuidado, ya que camino por un lugar lleno de espinas", Latrón respondió: "A fe mía que las espinas no están en el piso, sino en tus pies" y enseguida se puso a pronunciar sentencias, que habrían podido añadirse a los argumentos de la declamación de Marulo (Contr. I praef. 22).

\section{A sol y sombra}

Este hombre, que es reiteradamente considerado el mejor de los declamadores, no estaba a la altura de su elocuencia, si tenía que expresarse en un juicio real. El pasaje del ambiente cerrado de la escuela al bullicio del foro fue suficiente para anular su destreza oratoria:

Porcio Latrón, modelo único de virtud en la declamación, cuando pronunciaba en España un discurso en defensa de su pariente Porcio Rústico, fue presa de tal confusión que comenzó por un solecismo, y sintiendo la falta del techo y de las paredes no pudo recobrarse hasta que logró que el juicio fuera trasladado del foro a una basílica (Contr. IX, praef. 3).

Quintiliano (X, 5, 18) relata esta misma anécdota y concluye irónicamente sobre las dificultades del gran Porcio Latrón para hablar al aire libre: el cielo fue para él algo tan nuevo que toda su elocuencia parecía reducirse a un techo y unas paredes. ${ }^{35}$ 
Con Casio Severo ocurría lo contrario. Era un orador temible en el foro, pero mediocre en la declamación. Séneca le pregunta (Contr. III praef. 8) sobre las causas de este desempeño desigual y la respuesta de Severo es extensa (Contr. III praef. 8-18) e incluye el relato de su enfrentamiento com Cestio Pío, que referiremos luego. Por ahora transcribimos su lúcida visión de las condiciones y contextos diferentes en que se desarrollan la oratoria forense y la escolar:

Sin embargo, creo que puedo aducir una razón personal: ${ }^{36}$ estoy acostumbrado a atender al juez, no al auditorio; tengo la costumbre de responder a mi adversario, y no a mí mismo; no evito menos decir algo superfluo que algo que vaya contra mi causa; ien la declamación existe algo que no sea superfluo, siendo que ella misma lo es? Voy a decirte mi parecer: cuando hablo en el foro, estoy haciendo algo; cuando declamo (...) me parece que estoy trabajando en sueños. Luego la situaciones son completamente diferentes: una cosa es combatir, y otra, dar golpes al aire. (...) Ahora bien, lleva a esos declamadores al senado y al foro: verás que el lugar los cambia. Como los cuerpos acostumbrados a un lugar cerrado y a una suave sombra, ${ }^{37}$ no son capaces de permanecer a la intemperie, ni de tolerar la lluvia y el sol, apenas si pueden reconocerse a si mismos; se acostumbraron a ser elocuentes según sus propios criterios (Contr. III praef. 12-13).

El comentario de Severo podría aplicarse a la desdichada experiencia de Latrón en el foro. La oposición sol-sombra, presente como vimos en las dos narraciones del episodio de Latrón, es muy usual como imagen de las dos oratorias, la forense y la escolar o declamatoria. Consideremos algunos ejemplos. En los primeros capítulos del Satiricon de Petronio, la declamación se asocia al asianismo. (II, 3-5) La sombra, como imagen de la escuela, se opone a la sanidad del arte clásico griego. El retor, maestro de declamación, aparece como un umbraticus doctor, un sabio salido de la sombra, de la escuela, una figura risible, opuesta a la elocuencia sana de Sófocles y Eurípides, que habían encontrado las palabras con las que debían hablar. Aquellos tiempos de la gran poesía y oratoria griegas, afirma Petronio, no conocían estas escuelas: "Entonces los jóvenes no estaban encerrados en las declamaciones" ${ }^{38}$ (nondum iuvenes declamationibus continebantur). En Juvenal $(7,173)$, la escuela, figurada como umbra rhetorica se opone a los combates del foro, ${ }^{39}$ imagen que también recuerda el pasaje ya referido sobre Casio Severo. ${ }^{40}$ Quintiliano se refiere reiteradamente a la declamación, y adopta al respecto una solución de compromiso. ${ }^{41}$ La acepta como un medio, pero la rechaza como un fin en si mismo. Permanecer demasiado tiempo en el mundo falso de la escuela puede dificultar el paso al mundo real del foro: 
... no hay que retener a los jóvenes por demasiado tiempo en esta imagen falsa de la realidad, ni acostumbrarlos tanto a estos vanos simulacros que luego les sea difícil apartarse de ellos, y al dejar la sombra en la que, por así decirlo, han envejecido, teman a las disputas verdaderas como a una especie de sol (Quint. X, 5, 17).42

En resumen el uso de "sol" y "sombra" asociado a la dicotomía "oratoria forense - declamación", además de ser metonimia alusiva a las condiciones reales de dichas prácticas (el aire libre del foro, la oscuridad de una sala cerrada), funciona como metáfora que reduce la declamación a un papel epigonal. Si es verdad que en principio se trata de un entrenamiento, de una propedéutica a la oratoria, ya antes del surgimiento del imperio se desliga progresivamente de su origen ancilar, para convertirse en sustrato de otros géneros. La remisión a su origen oratorio, y la pretensión de realidad (verosimilitud forense) que le quiere imponer Quintiliano, revela su rechazo a lo que este género comienza a ser: un modelo para una nueva forma de decorum poético. Aun cuando recurra a argumentos exóticos, temas mitológicos y situaciones inverosímiles, la carga simbólica de éstos permite un nuevo tipo de acercamiento a la realidad.

\section{Casio Severo: la parodia de la parodia.}

Ya nos hemos referido a Casio Severo, y a la explicación que Séneca le atribuye de las diferencias entre oratoria y declamación. Su interpretación parece ser una versión más de la opinión común, que hemos visto desarrollada o aludida por Petronio, Quintiliano, Tácito y Juvenal. La continuación del relato de Séneca (Contr. III praef), con las palabras de Casio para justificar su desdén por la declamación, ofrecerán una escenificación de la oposición entre oratoria y declamación, semejante a un juego de espejos, en que realidad y parodia dejan de distinguirse con nitidez.

Casio (Contr. III praef. 14-15) introduce el problema del gusto. No es la elocuencia de los oradores, sino el juicio del público lo que se ha corrompido. Los jóvenes no solo prefieren al declamador Cestio antes que a Asinio Polión, Mesala Corvino y Pasieno, sino que lo anteponen al mismo Cicerón. De éste solo han leído los discursos a los que Cestio ha respondido. Quintiliano (X, 5, 20) reprueba la práctica de responder a los discursos de los antiguos, refiriendo el mismo ejemplo de Cestio. Este no estaría en condiciones de responder a Cicerón, porque a partir de su solo conocimiento de la defensa de Milón, no tendría los elementos suficientes para desarrollar el papel de la acusación. ${ }^{43}$ Severo, motivado por la arrogancia de Cestio, 
que se creía superior a Cicerón, concurre a su escuela cuando aquél se disponía a leer su discurso contra Milón (Contr. III praef. 16): ${ }^{44}$

Cestio admirando sus propias obras, como era su costumbre, decía: "Si yo fuera Tracio, sería un Fusio; si pantomimo, sería un Batilo; si caballo, un Melisio." No pude contener mi bilis y exclamé: "Si fueras una cloaca, serías la cloaca máxima". Risa genreral. Los alumnos se preguntaban quién sería ese caradura. Cestio, que se disponía a responderle a Cicerón, no encontró una respuesta para mí, pero dijo que no continuaría si yo no me retiraba. Respondí que no saldría de un baño público antes de haberme lavado. ${ }^{45}$

Casio ha comenzado su venganza de Cicerón, ridiculizando al pedante Cestio en su propia escuela. La virulencia del ataque es característica de la elocuencia de Casio, de acuerdo a los testimonios conservados sobre él. ${ }^{46}$ Para vengar a Cicerón, Casio continuará su ofensiva contra Cestio, ahora en los tribunales de justicia, su propio terreno. Pero las acusaciones que sucesivamente le endilga, se parecen más a las desarrolladas en las controversias, que a las propias de los juicios: Así convoca a Cestio ante el pretor y después de bromas e insultos varios, solicita abrir un proceso en su contra, con base en la ley de ofensa innominada (lege inscripti maleficii). ${ }^{47}$ Luego ante otro pretor lo acusa de ingratitud. ${ }^{48}$ Finalmente solicita al pretor urbano que le asigne un curador. ${ }^{49}$ Amigos comunes intentan mediar. Casio propone dejar de perseguirlo, con la condición de que Cestio jure que Cicerón es más elocuente que él. Cestio no acepta (cf. Contr. III praef.17).

Analicemos el episodio. Séneca le transfiere la palabra a Casio, con lo que el relato gana en vivacidad. Casio es el tipo de orador impulsivo y brillante, que trabaja mejor en la improvisación que en la preparación (Contr. III, praef. 5). ${ }^{50}$ Su ingenio se aguza cuando debe responder a un adversario. Por eso un joven orador de formación declamatoria, que prepara su discurso como una pieza literaria, y lo lee, en un juicio, despreocupado del contexto de enunciación, se convierte en víctima fácil de Casio, como en el siguiente ejemplo que refiere Quintiliano (VI, 1, 43):

“PPor qué, Severo, me miras con el rostro torvo?" "A fe mía que no lo estaba haciendo, respondió, pero ya que así lo has escrito, está bien” y se puso a mirarlo con la mayor truculencia de que fue capaz. ${ }^{51}$

En los absurdos procesos que Casio instituye contra Cestio, se lleva a cabo una parodia de la declamación. Para Casio la declamación es una torpe imitación de la 
oratoria. Al igual que Quintilano, rechaza el juego intertextual con que Cestio se enfrenta al texto de Cicerón. Sin embargo Casio no se limita a defender una jerarquía inmutable de los textos. Su propósito también es irreverente, porque mezcla dos géneros y sus convenciones. Casio responde em el mismo terreno que Cestio. Éste le respondía a Cicerón por medio de um ejercicio declamatorio. Casio, a su vez, adopta el tono, lenguaje y leyes imaginarias usuales en las controversias escolares, pero lo aplica a un juicio real. Al imitar procedimientos escolares Casio quiere demostrar la falta de realidad en las declamaciones, su insustancialidad. Sin embargo, la desproporción de su ataque a Cestio, el afán paródico y el humor corrosivo, son marcas de un estilo declamatorio, que une víctima y victimario en sus estrategias textuales.

El desvanecimiento del límite entre declamación y oratoria que surge del episodio nos recuerda la críticas que Mesala realiza (TAc. Dial. 26, 2-3) a la oradores contemporáneos: El estilo que emplean los abogados no le parece viril ni propio de oradores. La inmoderación en las palabras (lascivia verborum), la insustancialidad de las sentencias (levitate sententiarum), la excesiva libertad composicional (licentia compositionis) que Mesala les atribuye son rasgos que suelen considerarse propios del estilo declamatorio. ${ }^{52}$ Mesala deplora que la oratoria registre la desaparición de la distinción entre lo bajo y lo elevado. Las pantomimas y el arte de los histriones se confunden con la oratoria: nuestros oradores se expresan lánguidamente y nuestros histriones danzan elocuentemente. ${ }^{53}$ Mesala se refiere luego (Dial. 26, 4-6) a Casio Severo con un juicio matizado. Reconoce que puede ser llamado orador si se le compara a los que vinieron después de él $(26,3)$. Destaca en él la erudición, la elegancia y el vigor (Dial. 26, 6), pero reprueba su acritud (plus bilis habeat quam sanguinis) y lo denuncia como el primer orador que abandonó el orden en la composición, y suprimió la moderación y el pudor en las palabras. Añade que su obsesión por herir llegó a derribarlo muchas veces, y que esta actitud es más propia de una riña que de un combate (Dial. 26, 4). ${ }^{54}$ Es así que en el Dialogus de oratoribus Casio Severo, que Séneca había presentado como el enemigo de los declamadores, aparece como modelo de una estética declamatoria.

\section{Latrón, Albucio y el poder político}

No caben dudas de que el éxito de la declamación y su difusión son en parte deudores del impulso dado por Augusto a esta actividad. Desde el punto de vista de su relación con el poder político, la declamación puede analizarse desde dos ángulos aparentemente - contradictorios. Por un lado, la declamación parece alejarse de la realidad contemporánea en su búsqueda de temas y ambientes exóticos. Por otro, pa- 
rece que su separación de la oratoria forense y deliberativa amplió las posibilidades de expresar un registro crítico de la realidad. ${ }^{56}$ Referiremos ahora una anécdota registrada por Séneca el Viejo, relativa a Porcio Latrón. La misma es ilustrativa del modo en que los ejercicios declamatorios pueden convertirse en crítica política, pese al exotismo y a la aparente irrealidad de sus cuadros. La cuarta controversia del segundo libro presenta todas las características de extravagancia e inverosimilitud que se adjudican al género:

Un padre deshereda a su hijo. Éste se une a una cortesana y tiene de ella un hijo, al que acepta. Enfermo, manda buscar a su padre. Cuando éste llega, le recomienda a su hijo y muere. El padre, luego de la muerte de su hijo, adopta al niño. Su otro hijo lo acusa de demencia. ${ }^{56}$

Séneca transcribe los desarrollos sucesivos de los declamadores que representan, ya al padre que se justifica por haber adoptado a su nieto huérfano, ya al outro hijo, que lo acusa de demencia por haber aceptado como heredero al hijo de una meretriz (Contr. II, 4, 1-11). Nada parece más alejado de la realidad que esta sucesión de hechos patéticos e inverosímiles.

Sin embargo Séneca nos cuenta (Contr. II, 4, 12) que en esta controversia Latrón dijo algo inconveniente, no para la controversia, sino para sí mismo. Para que no queden dudas de que el sentido atribuíble a un texto siempre depende de sus circusnstancias de enunciación, Séneca nos informa que Latrón declamaba en presencia de Augusto, Agripa y Mecenas. Augusto adoptaría en los próximos días a los hijos de Agripa, sus nietos. Agripa, destacado general y gestor de la política augustea, no era de origen noble. $^{57}$

Cuando representaba el papel del joven, ${ }^{58}$ Latrón al tratar el tópico de la adopción dijo: "Ahora ese, que proviene del último escalón social, llega a la nobleza por medio de una adopción", y otras cosas del mismo tenor. Mecenas le indicó por señas a Latrón que el César tenía prisa, que terminara ya la declamación. Algunos pensaban que Mecenas había actuado con malicia; que lo había hecho no para que César no oyera lo que se había dicho, sino para que lo notara (Contr. II, 4,13$).{ }^{59}$

Latrón no fue acusado, probablemente porque resultó evidente que no había tenido intención de ofender. Por otra parte, Séneca destaca que no pudo excusar su error. Además intentar justificar una ofensa podía acabar por agravarla. ${ }^{60}$ Séneca elogia la tolerancia de Augusto y censura a aquellos que prefieren perder la cabeza y no la ocasión para un chiste. ${ }^{61}$ 
Albucio protagonizó un episodio análogo al de Latrón, pero no en una sala de declamación, sino en un proceso en Milán en el que defendía ante el procónsul Pisón a un acusado de asesinato. Ya hemos visto otra desdichada intervención suya en aquel juicio que perdió por hacer uso de un recurso retórico más adecuado a una controversia que a un juicio real. En esta ocasión Albucio hablaba en medio de los gritos de aprobación de sus simpatizantes. Los lictores trataron de hacerlos callar. Este, habituado como declamador a los aplausos que acompañaban los discursos, se irritó por la actitud de los lictores, y después de deplorar la situación de Italia, invocó a Bruto, cuya estatua estaba a la vista, como creador y protector de las leyes y de la libertad. Suetonio (De gram. et rhet. 30, 6) significa brevemente que Albucio pudo haber sido castigado, aunque no le ocurrió nada. ${ }^{62}$ La imprudencia de invocar al asesino de César ante un representante de Augusto es evidente, pero su actitud debe haber sido juzgada de modo análogo a la ofensa de Latrón a Agripa, más como una torpeza propia de declamador, que como una ofensa voluntaria.

En cualquier caso, ambos ejemplos muestran que el gusto por las figuras, el énfasis, las sentencias y los recursos propios del arte declamatorio, podían dar lugar a expresiones interpretables como críticas políticas, aun cuando no hubieran sido emitidas con tal intención. Si analizamos escritores de la edad imperial, como Juvenal y Tácito, habituados a los recursos de la alusión, y a los juegos de sentido, podemos concluir que el estilo declamatorio, convertido en cierto modo en la estética de la época, ofrecía la posibilidad de referir críticamente la realidad social y política, al tiempo que, si se usaba con cierta prudencia, podía proporcionar gracias a su ambigüedad, una salvaguarda para quienes escribían. ${ }^{63}$

\section{Notas}

* Professor de Língua e Literatura Latina da Universidad de la República (Montevideo, Uruguai) e Doutorando em Latim do Programa de Pós-Graduação em Letras Clássicas da FFLCH-USP.

1 También Quintiliano (III, 8, 53)refiere un ejercicio en el que el propio Sila se dirige al pueblo para anunciar que renuncia a la dictadura.

2 Et nos ergo manum ferulae subduximus, et nos / consilium dedimus Syllae, privatus ut altum / dormiret. La palmeta (ferula) alude a la enseñanza elemental, impartida en el aula del gramático. Las declamaciones, tanto las suasorias como las controversias, se practicaban en el aula del retor, equivalente aproximado de la actual enseñanza secundaria. Cf. también TAC. Dial. 35, 4-5. La traducción está tomada de Cicalese (Cicalese, 1999, p. 66). 
3 Sen. Contr. I praef. 12: Controversias nos dicimus: Cicero causas vocabat.

4 Cf. por ejemplo De or., I, 33, 149: Equidem probo ista, (Crassus) inquit, quae vos facere soletis, ut, causa aliqua posita consimili causarum earum quae in forum deferuntur, dicatis quam maxime ad veritatem accommodate. Se plantea una exigencia de verosimilitud para estos ejercicios, que deben construirse tomando como modelo la realidad del foro. En De or. II, 24, 100 se denuncia que las causae declamadas en escuelas son demasiado fáciles y que su práctica no tiene ninguna utilidad.

5 Cf. Suet. De gram. et rhet., 25, 3: Cicero ad praeturam usque etiam Graece declamitavit, Latine vero senior quoque et quidem cum consulibus Hirtio et Pansa, quos discipulos et grandis praetextatos vocabat.

6 Cf. Kennedy (Kennedy, 1972, p. 313) y Fairweather (Fairweather, 1984, p. 526-7 y 5434).

7 SEN. ib. ...ipsa declamatio apud nullum antiquum auctorem ante Ciceronem et Calvum inveniri potest qui declamationem $<$ a dictione $>$ distinguit [...]. Alterum putat domesticae exercitationis esse, alterum verae actionis.

8 Cic. Ib. 310: Commentabar declamitans (sic enim nunc loquuntur) saepe cum M. Pisone et cum Q. Pompeio aut cum aliquo cotidie... También en Tusc. II, 9 refiere a las argumentaciones dialécticas in contrarias partis como un excelente ejercicio.

9 Véase también Aul. Gel. XV, 11, 1.

10 Salvo indicación en contrario las traducciones nos pertenecen.

11 Suet. De gram. et rhet. 25,1: Cn. Domitius Ahenobarbus L. Licinius Crassus censores ita edixerunt: "Renuntiatum est nobis esse homines qui novum genus disciplinae instituerunt, ad quos iuventus in ludum conveniat; eos sibi nomen imposuisse Latinos rhetoras; ibi homines adolescentulos dies toto desidere. Maiores nostri quae liberos suos discere et quos in ludos itare vellent instituerunt. Haec nova quae praeter consuetudinem ac morem maiorum fiunt, neque placent neque recta videntur. Quapropter et his qui eos ludos habent et his qui eo venire consuerunt, videtur faciundum ut ostenderemus nostram sententiam, nobis non placere."

12 Cf. Cic. De or. III, 93, en que Craso presenta sus motivos: quos (i.e.: Latinos magistros dicendi) ego censor edicto meo sustuleram, non quo, ut nescio quos dicere aiebant, acui ingenia adulescentium nollem, sed contra ingenia obtundi nolui, corroborari impudentiam.

13 Ib.: At nunc adulescentuli nostri deducuntur in scholas istorum, qui rhetores vocantur, quos paulo ante Ciceronis tempora extitisse nec placuisse maioribus nostris ex eo manifestum est, quod a Crasso et Domitio censoribus cludere, ut ait Cicero, ludum impudentiae iussi sunt.

14 Ovidio se menciona varias veces en las controversias y suasorias. En Contr. II, 2, 8 se citan versos suyos, elaborados a partir de sentencias de Latrón. Ovidio prefería las suasorias, ejercicios que exigían menor desarrollo en la argumentación. Al declamar controversias, escogía aquellas en que era preciso retratar caracteres (cf. Contr. II, 2, 12). Este componente declamatorio es visible en su poesía, y está en la base de las críticas que ha recibido, en la antigüedad, y aun en tiempos más recientes.

$15 \mathrm{Ib}$.... quaedam etiam ad usum communis vitae instituta tum utilia et necessaria tum perniciosa et supervacanea ostendere.

16 Entre los declamadores, muchos tienen actuación destacada en el foro. Los relatos de Séneca el viejo testimonian la predilección de Augusto y su entorno por estos ejercicios. 
En ocasiones el propio emperador asistía a las declamaciones. Cf. por ejemplo Sen. Contr. II, 4, 12-13.

17 Cf. al respecto Kennedy (Kennedy, 1972, p. 312-322); Bonner (Bonner, 1977, p. 277 327); Winterbottom (Winterbottom, 1990, p. 12 y ss).

18 Cf. QUINT. II, 7, 1. Rhetor se había convertido en el nombre usual dado a los maestros de retórica, en cuyas alulas se practicaba la declamación.

19 Véase, por ej. Sen. Contr. III, praef. 16 en que Casio Severo visita la escuela de Cestio Pío; referiremos este episodio más adelante. Cf. también SEN. Contr. X, praef. que muestra el punto de vista de Labieno, declamador brillante, pero contrario a estas exhibiciones públicas, que aún no eran frecuentes, y él consideraba propias de una arrogancia frívola: declamavit (Labienus) non quidem populo, sed egregie. Non admittebat populum et quia nondum haec consuetudo erat inducta et quia putabat turpe ac frivolae iactationis.

$20 \mathrm{Ib} .:$ qui declamationem parat, scribit non ut vincat sed ut placeat. Omnia itaque lenocinia conquirit; argumentationes, quia molestae sunt et minimum habent floris, relinquit: sententiis, explicationibus audientis delenire contentus est. Cupit enim se adprobare, non causam.

21 En el Dialogus de oratoribus de Tácito, Apro defiende la necesidad de que el arte se adapte a los nuevos tiempos. Véase por ejemplo 19, 2, que refiere a Casio Severo: vidit (...) cum condicione temporum et diversitate aurium formam quoque ac speciem orationis esse mutandam.

22 SuET. ib.: Plerique autem oratorum etiam declamationes ediderunt. Quare magno studio hominibus iniecto magna etiam professorum ac doctorum profluxit copia adeoque floruit ut nonnulli ex infima fortuna in ordinem senatorium atque ad summos honores processerint.

23 Cf. TAC., Dial., 14, 4 y 42, 2.

24 Cf. especialmente Dial. 5, 4-7. Aunque la laus oratoriae en boca de Apro remita claramente a su similar de Craso en De or. I, 8, 31 y ss., su aparición en un contexto en que se discute sobre la elocuencia en la edad imperial, le otorga un valor que no puede ser reducido a mera cita.

25 Oratorum et rhetorum sententiae, divisiones, colores. Las sententiae son frases memorables que mediante la condensación del sentido y una predilección por las antítesis llaman la atención del oyente. Las divisiones constituyen las preguntas básicas que el declamador debía plantearse antes de desarrollar su tema, y que podían incluir desarrollos de iure, de aequitate, etc. Por ejemplo tenía el acusado derecho de actuar como actuó (de iure). En caso de respuesta afirmativa, era justo o adecuado que lo hiciera (de aequitate). Los colores refieren a la forma narrativa escogida para desarrollar el tema: un rasgo de un personaje, un móvil para una acción, todo lo que sirva para ilustrar la tesis sostenida.

26 I: Porcio Latrón; II: Papirio Fabiano; III: Casio Severo; IV: Asinio Polión y Quinto Haterio; VII: Albucio Silo; IX: Votieno Montano; X: Tito. Labieno.

27 Contr. VII praef. 6: quamvis paenituisset audisse, liberat audire.

28 Se esperaba normalmente que ocurriera lo contrario.

29 Era una práctica habitual. Otro ejemplo en Contr. III praef.17

30 i.e.: mi cliente. 
31 TAC. ib. ...iudices, qui vi et potestate, non iure aut legibus agnoscunt... cuya consideración de la oratoria pone énfasis en las ventajas personales y no en que en

32 Cf. TAc. Dial. 12, 2.

33 Veamos en Suetonio el pasaje previo a la propuesta de la fórmula para jurar: nam cum in lite quadam centumvirali adversario, quem ut impium era parentes incessebat, iusiurandum quasi per figuram sic obtulisset [...] (De gram. et rhet. 30, 5).

34 SEN. ib.: In utramque partem vehementi viro modus deerat: nec intermittere studium sciebat nec repetere.

35 Quint. X, 5, 18: Ita illi caelum novum fuit ut omnis eius eloquentia contineri tecto ac parietibus videretur. Es recurrente la imagen de declamadores habituados a la sombra e incapaces de soportar la luz del sol, es decir, las causas a cielo abierto, en el foro. Cf. por ejemplo, SEN. Contr. III, praef. 13.

36 Entiéndase, para su mediocre desempeños en las declamaciones.

37 Delicatae umbrae: el adjetivo podría traducirse también por afeminada, muelle. La calificación del estilo declamatorio como poco viril es recurrente en los textos antiguos relativos a la declamación. Veáse por ejemplo en TAc. Dial. 26, la referencia desdeñosa a los calamistros Maecenatis aut tinnitus Gallionis, los “oropeles de Mecenas o los tintineos de Galión”. Enseguida se asocia este estilo con vestimentas excesivamente acicaladas, propias de una meretriz (fucatis et meretriciis vestibus). Junio Galión fue un destacado declamador, amigo de Séneca y elogiadísimo en las Controversiae.

38 Cf. especialmente Sat. II, 3-5.

39 Juv. ib.: ad pugnam qui rhetorica descendit ab umbra. Obsérvese que el camino hacia el foro es descendente, y que tiene el único objetivo (cf. v. 174) de conservar la pequeña suma (summula ne pereat) necesaria para obtener una miserable ración de trigo (qua viles tessera venit / frumenti) (vv. 174). La oratoria no es un objetivo, sino una posiblidad remota de escapar a la miseria. El tono de esta sátira, con el desarrollo sucesivo de las profesiones intelectuales, destacadas en sus aspectos más miserables, es marcadamente declamatorio.

40 SEN. Contr. III praef. 13: totum aliud est pugnare, aliud ventilare. Cf. traducción supra. A decir verdad, imágenes y oposiciones muy similares aparecían ya en el Brutus (38) de Cicerón, referidas a Demetrio y a la escuela de Teofrasto (Teofrasti ... umbraculis).

41 Cf. Brink (Brink, 1989, p. 474-477).

42 En otro contexto, al tratar de los imitadores de los aticistas (XII, 10, 14-15), que no ahorraban críticas ni a Cicerón, y consideraban su árido purismo como una especie de religión, vuelve a aparecer la imagen del sol y de la sombra. La sombra está asociada aquí (XII, 10,15) al carácter epigonal de estos aticistas en relación al aticismo original: qui quia clariorem vim eloquentiae velut solem ferre non possunt, umbra magni nominis delitescunt "estos, como no pueden soportar la fuerza brillante de la elocuencia, que es como un sol, se ocultan a la sombra de un gran nombre".

43 Cf. Quint. ib.: Melius hoc [sc. causas vel easdem quas agi audierit componere, vel etiam alias, veras modo] quam rescribere veteribus orationibus, ut fecit Cestius actionem habitam pro eodem, cum alterarm partem satis nosse non posset ex sola defensione. 
44 Memini me intrare scholam eius cum recitaturus esset in Milonem. Se trata, pues, de una causa ficticia en la que Cestio iba a responder al famoso Pro Milone de Cicerón.

45 Cestius ex consuetudine sua miratus dicebat: si Thraex essem, Fusius essem; si pantomimus essem, Bathyllus essem, si equus, Melissio. Non continui bilem et exclamavi: si cloaca esses, maxima esses. Risus omnium ingens; scholastici intueri me, quis essem qui tam crassas cervices haberem. Cestius Ciceroni responsurus mihi quod responderet non invenit, sed negavit se executurum nisi exissem de domo. Ego negavi me de balneo publico exiturum nisi lotus essem.

46 En XI, 1, 57 Quintiliano critica la falta de decoro de Casio en la acusación. En XII, 10, 17 se refiere a su acritud, acerbitatem Cassi. Entre otras menciones de Quintiliano cf. VIII, 3, 89. Fue exiliado por Augusto, acusado de escribir textos difamatorios. Murió en Seriphos alrededor del año 34. En el Dialogus de oratoribus de Tácito, Apro y Mesala sostienen interpretaciones encontradas sobre su elocuencia.

47 No hay registros de la existencia de una ley semejante, pero procesos con base en ella aparecen en las controversias. Cf. Sen. Contr. V exc. 1, y Quint. I.O. VII, 4, 36.

48 Como en el caso anterior, los procesos por ingratitud parecen tener existencia sólo en las aulas de declamación. Cf. SEN. Contr. II, 5 y IX, 1.

49 Aunque existía la posibilidad de solicitar un curador para quien no estuviera en su sano juicio, es también un tema de controversia. Cf. Contr. II, 4 y II, 6.

50 Uni illi proderat excuti; melius semper fortuna quam cura de illo merebatur.

51 Transcribimos el texto traducido y su contexto anterior: Ex scholis haec vitia, in quibus omnia libere fingimus et impune, quia pro facto est quidquid voluimus; non admittit hoc idem veritas, egregieque Cassius dicenti adulescentulo: "Quid me torvo vultu intueris, Severe?" "Non mehercule, inquit, faciebam, sed sic scripsisti: ecce!" et quam potuit truculentissime eum aspexit.

52 A menudo se ha señalado críticamente su presencia en escritores del período posclásico. Véase por ejemplo la caracterización crítica de la composición en las sátiras de Juvenal en de Decker (de Decker, 1913, p. 83-90 y passim). Cf. también Morton (Morton, 1997).

53 Cf. Dial. 26, 3: Quodque vix auditu fas esse debeat, laudis et gloriae et ingenii loco plerique iactant cantari saltarique commentarios suos (...) ut oratores nostri tenere dicere, histriones diserte saltare dicantur.

54 TAC. Dial. 26, 3-4: Equidem non negaverim Cassium Severum (...) si iis compararetur, qui postea fuerunt posse oratorem vocari, quamquam in magna parte librorum suorum plus $b$ [il] is habeat quam sanguinis. Primus enim contempto ordine rerum, omissa modestia ac pudore verborum, ipsis etiam quibus utitur armis incompositus et studio feriendi plerumque deiectus, non pugnat, sed rixatur.

55 Véase por ejemplo sobre la declamación y su función crítica en la primera sátira de Juvenal, véase Cicalese (Cicalese, 1999, p. 119-130)

56 Contr. II, 4: Abdicavit quidam filium; abdicatus se contulit ad meretricem; ex illa sustullit filium. Aeger ad patrem misit: cum venisset, comendavit ei filium suum et decessit. Pater post mortem illius adoptavit puerum; ab altero filio accusatur dementiae.

57 Cf. Contr. II, 4, 12: Erat M. Agrippa inter eos, qui non nati sunt nobiles, sed facti.

$58 \mathrm{El}$ hermano del muerto, que acusa al padre de demencia. 
59 Ib.: Cum diceret partem adulescentis Latro et tractaret adoptionis locum, dixit: "iam iste ex imo per adoptionem nobilitati inseritur" et alia in hanc summam. Maecenas innuit Latroni festinare Caesarem; finiret iam declamationem. Quidam putabant hanc malignitatem Maecenatis esse; effecisse enim illum non ne audiret quae dicta erant Caesar, sed ut notaret. 60 Véase um análisis de este episodio en Bartsch (Bartsch, 1994, p. 82-84).

61 Cf. Contr. II, 4, 13: Mihi videtur admiratione dignus divus Augustus, sub quod tantum licuit, sed horum non possum misereri, qui tantum putant caput potius quam dictum perdere.

62 Cf. ib.: paene poenas luit.

63 Cf. Ahl (Ahl, 1984).

\section{REFERÊNCIAS BIBLIOGRAFICAS}

AHL, F. The Art of Safe Criticism in Greece and Rome. American Journal of Philology. Baltimore, v. 105, p. 174-208, 1984.

BARTSCH, S. Oppositional Innuendo: Performance, Allusion and the Audience. Actors in the Audience. Theatricality and Doublespeak from Nero to Hadrian. Cambridge: Harvard University Press, 1994, p. 63-97.

BONNER, S. F. Education in Ancient Rome. Berkeley and Los Angeles: University of California Press, 1977.

BRINK, C. O. Quintilian's De causis corruptae eloquentiae and Tacitus'Dialogus de oratoribus. Classical Quarterly. Oxford, v. 39, p. 472-503, 1989.

CICALESE, V. O. Juvenal, su tiempo y sus sátiras. Montevideo: Universidad de la República, 1999.

DE DECKER, J. Juvenalis Declamans. Gand: Livraire Scientifique E. Van Goethem, 1913.

KENNEDY, G. The Art of Rhetoric in the Roman World. New Jersey: Princeton University Press, 1972.

MORTON, S. Declamation and Contestation in Satire. In: DOMINIK W. J. Roman Eloquence. Rhetoric in Society and Literature. London: Routledge, 1997, p. 147-165.

NORDEN, E. La prosa d'arte antica dal VI secolo all'età della rinascenza. Roma: Salerno Editrice, 1986. 2v. (1 ${ }^{a}$ ed. 1898).

WINTERBOTTOM, M. Roman Declamation. Bristol: Bristol Classical, 1990 
SCHWARTZ, Pablo. Déclamation et Oratoire sous Auguste: à propos de Albucius Silus, Porcius Latron et Cassius Sévérus.

RÉSUMÉ: Sénèque l'Ancien présente le portrait le plus complete duquel on dispose sur la déclamation en Rome. Cette pratique, considerée comme un exercice d'école qui prépare les jeuns gens à l'éloquence judiciaire ou deliberative devient en genre indépendant. Ce fait, de vastes conséquences pour l'histoire de la littérature occidentale, est analysée en partant des performances de trois orateurs et declamateurs: Albucius Silus, Porcius Latron et Cassius Sévérus. Ces exemples montrent une relation tendue entre déclamation et oratoire, mais aussi laissent voir une éloquence adaptée à l'expression du temps présent.

MOTS-CLEFS: Sénèque le Rhéteur; déclamation; éloquence; oratoire. 